\section{From the authors:}

We are grateful to J. Nasiłowski and colleagues for having pointed out the important problem of the use of noninvasive ventilation (NIV) in Eastern European countries. Unfortunately, we were unaware of the survey conducted in Poland [1], mentioned by the authors, simply because it was not found using any medical search engine (i.e. Pubmed and similar).

We agree with J. Nasiłowski and colleagues that the use of NIV may be different in some geographical locations. However, as stated in the Methods section of our study: "The survey was sent to all members of the Respiratory Intensive Care Assembly from the European Respiratory Society (ERS), members of the Acute Respiratory Failure Group from the European Society of Intensive Care Medicine (ESICM), and physicians working in the emergency department (ED) known to be involved in NIV practice or to have published articles on the topic" [2]. This means that, as pointed out by the authors and as we stated in the Strengths and limitations section of our manuscript, our data cannot be generalised, as we may have missed physicians who are not members of any of these associations. Thus, surveying individuals meeting specific criteria (members of European societies) may have biased the results, but the use of associations' rosters to send out these surveys is common practice for this type of study; therefore there is an a priori bias that could not be easily solved.

Finally, we would like to point out that, as stated in the manuscript's introduction section, the primary aim of our study was to characterise the pattern of NIV utilisation, "placing emphasis on the technical aspects of NIV use" [2] (ventilator and interface type) in different scenarios among European NIV users, rather than identify the prevalence of NIV utilisation in European countries per se.

Concerning the specific points raised by J. Nasilowski and colleagues, we have the following comments.

1) "[The authors] arbitrarily divided Europe geographically into Northern, Central and Southern regions". This division has been employed by several other surveys [3, 4] and is therefore commonly accepted.

2) "[...] only 16 departments/wards (35\% of responders) had been providing NIV to patients with respiratory failure." We do not see a large difference between these data and the results of our survey $(52.9 \%$ of pulmonologists reported $>20 \%$ of patients treated with NIV per yr versus $34.3 \%$ intensivists/ anaesthesiologists and $12.6 \%$ others).
3) "The study [...] represents the extent of NIV use among European leaders in NIV treatment". We respectfully disagree with this point. Being a member of a scientific association does not necessarily mean that you are an expert. About $3 \%$ of our respondents stated that they had no experience with NIV, and the large majority of the intensivists reported treatment of a small percentage of patients (see point 2). Indeed, of the 272 respondents, only a small minority $(\sim 15-20 \%)$ have published at least one paper on the subject, confirming that our survey mainly reflects daily "perceived" practice, rather than an "elite" snapshot.

\section{Crimi*, A. Noto\#, P. Princi ${ }^{\top}$, A. Esquinas ${ }^{+}$and S. Nava ${ }^{\S}$} *Dept of Internal and Specialistic Medicine, Section of Respiratory Diseases, Azienda Ospedaliera Universitaria Policlinico "G. Rodolico", University of Catania, Catania, "Dept of Cardiothoracic and Vascular Anesthesia, Azienda Ospedaliera Universitaria "G. Martino", University of Messina, "National Research Council, Messina, ${ }^{\S}$ Respiratory and Critical Care Unit, Azienda Ospedaliera Universitaria Sant' Orsola-Malpighi, Bologna, Italy, and 'Intensive Care Unit, Hospital Morales Meseguer, Murcia, Spain.

Correspondence: S. Nava, Respiratory and Critical Care Unit, Azienda Ospedaliera Universitaria Sant' Orsola-Malpighi, Via Massarenti no. 9, 40138 Bologna, Italy. E-mail: stefano. nava@aosp.bo.it

Statement of Interest: Statements of interest for P. Princi and S. Nava can be found at www.erj.ersjournals.com/site/misc/ statements.xhtml

\section{REFERENCES}

1 Nasiłowski J, Leszczyk M, Bura M, et al. [A survey of noninvasive ventilation use in respiratory departments in Poland.]. Pneumonol Alergol Pol 2010; 78: Suppl. 1, 43.

2 Crimi C, Noto A, Princi P, et al. A European survey of noninvasive ventilation practices. Eur Respir J 2010; 36: 362-369.

3 Sprung CL, Cohen SL, Sjokvist P, et al. End-of-life practices in European intensive care units: the Ethicus Study. JAMA 2003; 290: 790-797.

4 Nava S, Sturani C, Hartl S, et al. End-of-life decision-making in respiratory intermediate care units: a European survey. Eur Respir J 2007; 30: 156-164.

\title{
Sleep apnoea in Asians and Caucasians: comparing apples and oranges
}

To the Editors:

We read with great interest the recent study in the European Respiratory Journal by YAMAGISHI et al. [1]. The study sheds new light on our understanding of ethnic differences in susceptibility to obstructive sleep apnoea (OSA). Previous studies have shown consistently that among patients referred to sleep laboratories, Asians present a higher apnoea/hypopnoea index (AHI) than Caucasians matched for age and body mass index (BMI). Conversely, when matched for AHI, Asians have a lower BMI 